\title{
Mapeamento dos lineamentos estruturais do sertão central do Ceará com ênfase na espacialização dos inselbergs do batólito de Quixadá
}

\author{
Mapping of structural lineaments of the central hinterland of Ceará with emphasis on \\ specialization of inselbergs the batholith of Quixadá. \\ CASTRO $^{1}$, H. S.; MAIA ${ }^{2}$, R. P.; VERISSIMO ${ }^{1}$, C. U. V.; VIEIRA ${ }^{2}$, L. F. \\ henrique-sdc@hotmail.com
}

\begin{abstract}
Resumo
Este trabalho tem com interesse, argumentar a importância que a morfotectônica exerce nas paisagens do nordeste brasileiro. Para o caso, apresentamos, o mapeamento dos lineamentos estruturais da área circundante ao batólito de Quixadá, na região do sertão central do Ceará, na intensão de identificar padrões regionais de lineamentos que perpassam o batólito. Fornecendo assim, argumentos estruturais para a espacialização dos inselbergs. O texto mostra os passos que foram essenciais para esta empreitada, no desenvolvimento das argumentações e, do mapa, como produto final.
\end{abstract}

Palavras-chave: Mapeamento Estrutural, Morfotectônica, Quixadá.

\begin{abstract}
This work is of interest to argue the importance of morphotectonic exercises in northeastern Brazil landscapes. In the case presented, the mapping of structural lineaments of the area surrounding the batholith of Quixadá, in the region of the central hinterland of Ceará, in the intention of identifying regional lineaments standards that pervade the batholith. Thus providing structural arguments for the spatial distribution of inselbergs. The text shows the steps that were essential to this effort in the development of arguments, and the map as a final product.
\end{abstract}

Keywords: Structural mapping, Morphotectonic, Quixadá.

\section{INTRODUÇÃO}

A área está localizada geotectonicamente na margem nordeste da Plataforma Sul Americana (Almeida, et al. 1981, 2000), na parte Setentrional da Província da Borborema (|PB), segundo a divisão de Trompette (1994), e na subdivisão do Domínio Ceará Central (DCC) proposta por Fetter et al., (2000).

Fetter et al. (2000), baseado em dados geocronológicos usando o método Sm-Nd em rocha total e U-Pb em grãos de zircão subdividiu os terrenos do Ceará Central, que estão contidos na PB, em grupos tectônicos, que correspondem: um núcleo Arqueano (Maciço de Tróia - Pedra Banca), terrenos acrescionários Paleoproterozóicos e como consequência da orogenia do Neoproterozóico, sequências supracrustais relacionadas com o Grupo Ceará, o Complexo Tamboril-Santa Quitéria (Arco magmático) e muitos plutons graníticos (como no caso de Quixadá).

Em descrição mais atual Arthaud (2008) reclassifica estas quatro unidades, subdividindo-as em: a) embasamento policicíclico (Complexo Cruzeta e Sequência Choró-Algodões); b) coberturas 
metassedimentares monocíclicas (Grupo Ceará); c) complexo anatético-ígneo monocíclico (Complexo Tamboril-Santa Quitéria); d) granitos brasilianos e molassas tardi-brasilianas.

O evento tectônico de edificação de Gondwana Oeste (Araújo, 2014) foi o principal responsável pela formação das estruturas geológicas (zonas de falhas, litotipos) vistas na Província da Borborema.

A província geotectônica da Borborema foi formada dentro do contexto do corredor tectônico Transbrasiliano-kandi, como proposto por Cordani et al., (2013), onde com o fechamento do Oceano Goiás-Farusiano formou as colagens supercontinentais neoproterozóicas / início do paleozoico - Brasiliana/Pan-Africana, anteriormente, trabalhada por Arthaud (2007) e Amaral (2010). Para nossa realidade geológica cearense, a possível sutura é, a Zona de Cisalhamento Sobral Pedro II (Lineamento Transbrasiliano) entre os blocos crustais do Domínio do Médio Coreaú e Domínio do Ceará Central.

$\mathrm{Na}$ sequência como também elencaram Maia e Castro (no prelo), dois outros eventos tectônicos influenciaram na edificação dos terrenos e nos processos erosionais do Nordeste do Brasil. Um no cretáceo, que resultou na abertura Brasil- África, (PEULVAST E CLAUDINO SALES, 2006, 2008) e, outro no cenozoico, o magmatismo responsável pelo alçamento do planalto da Borborema e vários intrusões no NE brasileiro (OLIVEIRA, 2008).

No trabalho de Maia et al. (2014), abordam que as paisagens vislumbradas hoje, são um recorte momentâneo, de uma dinâmica regrada pelo tempo geológico, onde no mesmo, inumeráveis variações climáticas aconteceram. Nesse contexto, grande espessura de material rochoso foi exumado, algumas dezenas de quilômetros, concordando com Arthaud (2007) e Amaral (2010), com isso, litologias e estruturas dúcteis originadas em grandes profundidades, hoje são afloramentos em superfície, no caso, os relevos residuais/estruturais.

\section{METODOLOGIA}

São três pilares para o desenvolvimento deste trabalho, que serão citados sem ordem de importância, e claro, a falta de um deles comprometeria de veras ou, até inviabilizaria a produção do mesmo, são eles: revisão bibliográfica, experiência de campo e as ferramentas disponíveis na geotecnologia.

Na revisão bibliográfica, foram acessados trabalhos de Almeida, 1995; Nogueira, 2004; Arthaud, 2007; Maia e Bezerra, 2014 e Maia et al 2014: as cartas foram MAPA GEOLÓGICO FOLHA QUIXADÁ SB.24-V-B ESCALA 1:250.000 - CPRM, 2007 PROGRAMA GEOLOGIA 


\section{DO BRASIL INTEGRAÇÃO GEOLÓGICA REGIONAL, MAPA GEOLÓGICO FOLHA} QUIXERAMOBIM SB.24-V-D-III ESCALA 1:100.000 - UFC/CPRM - 2008, Cavalcante,2003.

Durante todo o momento de extração dos lineamentos estruturais em ambiente SIG, os arquivos shapefiles disponibilizados pela CPRM e, as descrições dos artigos e teses, forram de grande auxilio para vislumbrar os lineamentos estruturais. O conhecimento de campo, foi importante para extração dos lineamentos no momento da etapa de escritório (revisão da produção cartográfica/ bibliográfica e a produção do mapa).

\section{RESULTADOS E DISCUSSÃO}

A pesquisa aqui proposta, está espacialmente localizada nas proximidades do município de Quixadá, no estado do Ceará, Nordeste do Brasil. Tem como foco, extrair os lineamentos estruturais que perpassam o batólito de Quixadá. O interesse é, relacionar a disposição espacial dos inselbergs com os lineamentos regionais.

$\mathrm{Na}$ confecção do mapa de lineamentos, foram extraídos no caso, só as cristas (os vales, consequentemente estão encaixados nas cristas). Foram usadas imagens da Shuttle Radar Topography Mission (SRTM) com pixel de trinta metros, da National Aeronautics and Space Administration (NASA). O Batólito de Quixadá, está especializado na junção de quatro folhas da SRTM.

As quatro folhas foram trabalhadas no Global Mapper 16.0. Inicialmente, foi feito um mosaico, com quatro cenas diferentes. Todas as cenas, estão posicionadas em relação a luz, a 70 graus de altitude e variando os graus de azimute $(0,45,90,135)$. Depois foram salvas, as quatro cenas do mesmo recorte e, trabalhadas no Arcgis 10.4, onde os shapes de lineamentos foram gerados manualmente.

As cenas que foram geradas com ângulos azimutais diferentes, auxiliaram fazendo sobras no relevo, ressaltando assim, os lineamentos estruturais. A cena com azimute de $0^{\circ}$, fará sombra de direção E-W; a cena com azimute $45^{\circ}$ fará sombra com direção NW-SE; a cena com azimute de $90^{\circ}$ fará sombra com direção N-S e a cena com azimute de $135^{\circ}$ fará sombra de direção NE-SW. Essa última cena, foi a que mais ajudou na extração dos lineamentos pois as cinemáticas estruturais de maior presença, estão direcionadas de NE-SW. No mapa, a imagem SRTM usada, está com a composição de cores em escala de cinza, com o ângulo de visada posicionada em relação a luz, a $70^{\circ}$ graus de altitude e com $135^{\circ}$ de azimute, pois assim as feições de relevo são bem mais destacadas (o relevo apresenta a maior quantidade de direcionamentos a NE).

Para auxiliar a identificação das estruturas, também foi feito no Global Mapper, algumas composições de cores para as altimetrias, pois foi percebido que os lineamentos estruturais estão 
sustentando muitas cristas, ou altos topográficos, que são os divisores da bacia hidrográfica da área. As cristas se correlacionam com os lineamentos, os vales também estão por vezes, encaixados nos lineamentos (drenagens de menor porte), isso não é uma regra, muitas sobreposições dos vales perpassam as estruturas impressas na geologia do terreno, mas como já dito, os vales não foram extraídos, pois aqui, o foco são as cristas e os altos topográficos, que são os divisores das bacias hidrográficas e, essas, são as divisões de denudação dos relevos, tendo com fato, que os rios são as principais calhas de transporte de materiais rochosos desagregados.

Os lineamentos aqui extraídos, são parte de deformações dúcteis, impressas na paisagem como cristas (MAIA e BEZERRA, 2014). Para a identificação das estruturas, são melhores escalas menores. Aqui, usamos o mosaico do Nordeste Setentrional (SRTM,30m) para visualização e entendimento da cinemática regional, que está impressa na paisagem. Os lineamentos foram extraídos com escala grandes, dando zoom nas estruturas a serem marcadas, para maior riqueza de detalhes. Optado foi não fixar uma escala, pois para o tamanho da área aqui analisada a escala seria muito pequena e, a riqueza de detalhes aqui buscada, não seria alcançada.

As estruturas mapeadas como lineamentos estruturais são da tectônica da formação de Godwana Oeste, (ARTHAUD, 2007; ARAÚJO, 2014). O batólito de Quixadá, como dito por Almeida (1995), de acordo com a associação mineralógica, é uma suíte shoshonítica pós colisional e diz: "Sua forma diapírica é ressaltada pelas foliações internas paralelas aos contatos e ás foliações externas, formando na sua porção norte um 'trende' circular, indicando um baloneamento 'in situ'. ”.

Não são muitas as marcas deixadas pela edificação geotectônica brasiliana (ARTHAUD, 2007) no batólito de Quixadá, por ser pós colisional. Mas, ainda assim, é perceptível que a disposição dos relevos graníticos, inselbergs, dentro do batólito estão especializadas paralelas as zonas de cisalhamento Senador Pompeu e Quixeramobim (NE-SW).

A seguir, o Mapa de Lineamentos Estruturais do Sertão Central- CE, esse é o produto final gerado nesta empreitada. Em destaque, as duas principais zonas de cisalhamento que influenciam na cinemática regional dos lineamentos estruturais do terreno. A zona de Cisalhamento Senador Pompeu foi extraída de acordo com a cartografia da CPRM (já referenciada). A zona de cisalhamento Quixeramobim, que ainda não tem seus limites demarcados com muita acurácia, foi inferida pelos autores com auxílio das cartografias e bibliografias já referenciadas (Mapa 01). 


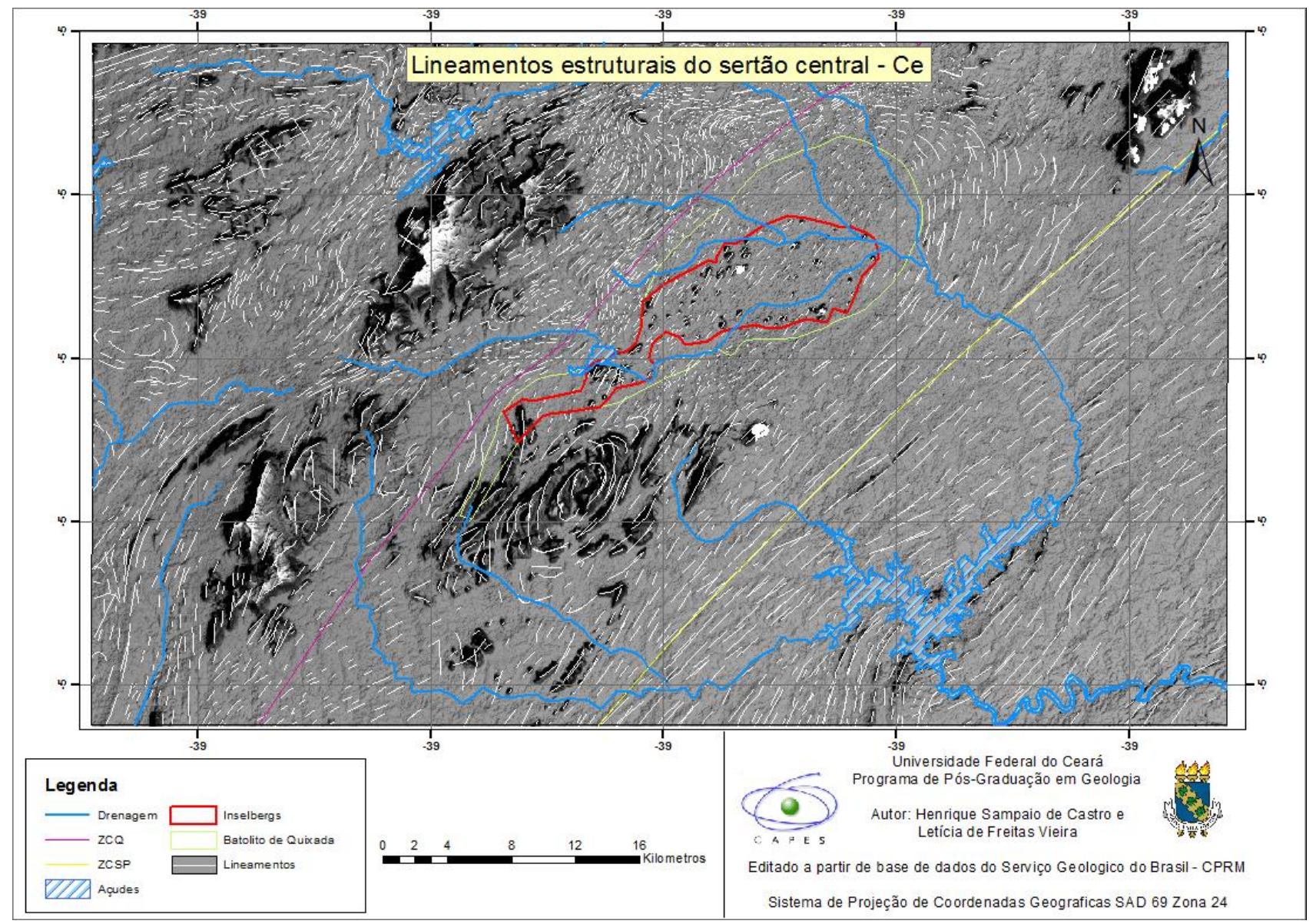

Mapa 01. Lineamentos estruturais do sertão central do Ceará. Fonte: Castro, H.S. \& Vieira, L.F (2016).

\section{CONSIDERAÇÕES FINAIS}

A metodologia se mostra muito eficácia para extração de lineamentos estruturais. Foi destacado, que a tectônica passada tem influência significativa na estruturação da atual paisagem. Onde na parte confrontante NW do batólito de Quixadá, há uma grande dinâmica de cavalgamento de "nappes" com presença de várias zonas de cisalhamento contracionais, também a NW, está a zona de cisalhamento dextral de Quixeramobim (NE-SW); do lado SE- L-NE a zona de cisalhamento Senador Pompeu (NE-SW) exerce controle estrutural regional. Os inselbergs apresentam-se espacializados preferencialmente a NE, ainda que a tectônica, não tenha impresso grandes marcas no batólito, por esse ter sido pós orogênico, ainda assim é percebida a influência dos lineamentos, orientados segundo a direção das duas zonas de cisalhamentos agora citadas. Assim, mostra-se nítida a importância dos estudos da morfotectônica na estruturação das paisagens. 


\section{REFERENCIAS}

ALMEIDA, A.R. Petrologia e Aspectos Tectônicos do Complexo Granítico QuixadáQuixeramobim - CE. 1995. 279 f. Tese (Doutorado em Geociências)- Instituto de Geociências, Universidade de São Paulo. São Paulo, 1995.

ALMEIDA F.F.M., HASUI Y, BRITO NEVES B.B., FUCK R.A. Brazilian structural provinces: an introduction. Earth Science Reviews, n.17, p 1-29, 1981.

ALMEIDA, F.F.M; BRITO NEVES, B.B; CARNEIRO, C.D.R. The origin and evolution of the South American Platform. Earth-Science Reviews. n. 50, p 77-111, 2000.

AMARAL, W.S. Análise geoquímica, geocronológica e termobarométrica das rochas de alto grau metamórfico, adjacentes ao arco magmático de Santa Quitéria, NW da Província Borborema. 2010. Tese de Doutorado, Universidade Estadual de Campinas-UNICAMP.

ARAÙJO, C.E.G. Evolução Tectônica da Margem ativa Neoproterozóica do Orógeno Gondwana Oeste na Província Borborema (NE-Brasil). Tese de doutorado/ Programa de Pós Graduação em Geoquimica e geotectônica do instituto de Geociencias da Universidade de São Paulo. 2014. 243 p.

ARTHAUD, M.H. Evolução Neoproterozóica do Grupo Ceará (Domínio Ceará Central, NE Brasil): da sedimentação à colisão continental brasiliana. 2007. Tese de Doutorado, Instituto de Geociências, Universidade de Brasília, Brasil.

CAVAlCANTE, J. C. et al. Mapa geológico do Estado do Ceará - Escala 1:500.000. MME/CPRM. 2003.

CLAUDINO-SALES, V. Evolução morfoestrutural do relevo da margem continental do Estado do Ceará, Nordeste do Brasil. Revista Caminhos de Geografia. Uberlândia. V. 7, n. 20. p,1-2. 2007. CORDANI, U. G.;PIMENTEL, M.M.; ARAÚJO C.E.G.; FUCK, R.A. The significance of the Transbrasiliano-Kandi tectonic corridor for the amalgamation of West Gondwana. Brazilian Journal of Geology, v.43, p. 583-597, 2013.

FETTER, A.H.; SCHMUS, W.R.V.; SANTOS, T.J.S.; NETO, J.N.N.; ARTHAUD, M.H. 4 UPb and Sm-Nd geochronological constraints on the crustal evolution and basement architecture of Ceará State, NW Borborema Province, NE Brazil: implications for the existence of the Paleoproterozoic Supercontinent "Atlantica”. Revista Brasileira de Geociências, São Paulo, v. 30, n. 1 , p. 102-106, 2000.

MAIA, R.P e BEZERRA, F. H.R. Tópicos de Geomorfologia Estrutural: Nordeste Brasileiro. V.1. Fortaleza: Ed. UFC, 2014. 
MAIA, R. P.; NASCIMENTO, A.M.L.; BEZERRA, F. H. R.; CASTRO, H.S.; MEIRELES, A.J.A.; ROTHIS, L.M. Geomorfologia do campo de inselbergues de Quixadá - NE do Brasil. Revista Brasileira de Geomorfologia, N16, Vol.2, 2015.

MAIA,R.P e CASTRO, H.S. Erosão diferencial e propriedades geomorfológicas das rochas exemplos do Ne brasileiro. Revista de Geociências do Nordeste. (no prelo).

MAPA GEOLÓGICO FOLHA QUIXADÁ SB.24-V-B ESCALA 1:250.000 - CPRM, 2007 PROGRAMA GEOLOGIA DO BRASIL INTEGRAÇÃO GEOLÓGICA REGIONAL.

MAPA GEOLÓGICO FOLHA QUIXERAMOBIM SB.24-V-D-III ESCALA 1:100.000 UFC/CPRM - 2008,

NOGUEIRA, J.F. Estrutura, geocronologia e alojamento dos batólitos de Quixadá, Quixeramobim e Senador Pompeu - Ceará Central. Tese (Doutorado em Geologia)- Instituto de Geociências e Ciências Exatas da Universidade Estadual Paulista. Rio Claro, 2004

OLIVEIRA, R.G. Arcabouço geofísico, isostasia e causas do magmatismo Cenozóico da Província Borborema e de sua margem continental. Tese de Doutorado (Geodinâmica e Geofísica), 400p. Universidade Federal do Rio Grande do Norte, Natal, 2008.

PEULVAST, J. P.; CLAUDINO SALES, V. Reconstruindo a evolução morfotectônica da margem passiva do Nordeste brasileiro. In: SILVA, J.B.; LIMA, L.C.; ELIAS, D. (Orgs.). Panorama da Geografia Brasielira. 1 ed.: São Paulo. Anna Blume, 2006, v. 1, p. 47-99, 2006.

PEULVAST, J.P.; CLAUDINO, S. V; Bétard, F.; Gunnell, Y. Low post Cenomanian denudation depths across the Brazilian Northeast:Implications for long-term landscape evolution at a transform continental margin. Global and Planetary Change. N. 62, p. 39-60.2008.

TROMPETTE, R. Geology of Western Gondwana, Pan African-Brasiliano aggregation of South America and Africa. Rotterdam: A. A. Balkema, 1994. 350 p.

Recebido em: 14/08/2016

Aceito para publicação em: 01/10/2016 